\title{
FORMAÇÃO INICIAL DE PROFESSORES E O CURSO DE PEDAGOGIA: REFLEXÕES SOBRE A FORMAÇÃO MATEMÁTICA
}

\author{
'Teachers' initial education and the pedagogy \\ of Undergraduate Orograms: reflections \\ on Mathematical formation
}

Marlisa Bernardi de Almeida ${ }^{1}$. Maria das Graças de Lima ${ }^{2}$

\begin{abstract}
Resumo: O presente artigo investiga a formação inicial matemática recebida pelos alunos concluintes do curso de Pedagogia para o exercício da docência em matemática nas séries iniciais do Ensino Fundamental, buscando levantar questionamentos e discussões referentes a essa formação. A metodologia utilizada privilegia a pesquisa qualitativa. Os resultados revelam que a formação ofertada no curso de Pedagogia relega a formação matemática para o segundo plano, sendo totalmente insuficiente para atender as necessidades da formação inicial. A investigação nos alerta que os organizadores do currículo do curso de Pedagogia precisam urgentemente repensar a forma como vem acontecendo a dinâmica de trabalho referente à formação matemática de seus alunos ao longo do curso.
\end{abstract}

Palavras-chave: Formação de professores. Pedagogia. Ensino superior. Ensino de matemática.

\begin{abstract}
The present article seeks to investigate the mathematical initial formation received by students who are concluding the course of Pedagogics for teaching in Mathematics in the Initial Series of Basic School, seeking to raise questionings and issues with this formation. The methodology used is qualitative research in interlocution rather than a quantitative one. The results disclose that historically the course in Pedagogics is large, and that mathematical formation is relegated so that the load is insufficient to take care of the necessities of the initial formation. The inquiry alerts one that the coordinators of the resume of the course of Pedagogics urgently need to rethink the course especially the Mathematical formation of its pupils throughout the course.
\end{abstract}

Key words: Initial formation of Teacher. Mathematical formation. Course of Pedagogic.

\footnotetext{
${ }^{1}$ Rede Pública do Estado do Paraná. Rua Getúlio Vargas, 710, Centro. Laranjeiras do Sul, PR, Brasil. 85.301-110. marlisabernardi@yahoo.com.br

${ }^{2}$ Programa de Pós-Graduação em Educação para a Ciência e o Ensino da Matemática, Universidade Estadual de Maringá. Maringá, PR, Brasil.
} 
Almeida, M. B.; Lima, M. G.

\section{Introdução}

Entende-se que a formação inicial de professores está inserida em um contexto mais amplo de formação, a qual traz, em seu processo histórico avanços e retrocessos.

Atualmente, no Brasil, a responsabilidade pela formação do professor dos anos iniciais está centrada nos cursos de Pedagogia. Mas, historicamente, nem sempre foi assim.

O curso de Pedagogia foi criado no Brasil em 1939, como consequência da preocupação com o preparo de docentes para a escola secundária, e não para a escola primária, pois a formação desses professores se fazia, exclusivamente, nas Escolas Normais.

O curso de Pedagogia, ao longo de sua história, como aponta Silva (1999), teve definidos, como seu objeto de estudo e finalidade precípuos, os processos educativos em escolas e em outros ambientes, sobremaneira a educação de crianças nos anos iniciais de escolarização, além da gestão educacional. Merece ser salientado que, nas primeiras propostas para este curso, a ele se atribuiu o estudo da forma de ensinar, definido, inicialmente, como lugar de formação de técnicos em educação.

Um dos marcos importantes para o curso de Pedagogia foi o parecer do Conselho Federal de Educação (CFE) no 252, de 11 de abril de 1969 (BRASIL, 1969a), de autoria do professor Valnir Chagas, membro do Conselho Federal de Educação. Esse parecer foi acompanhado da Resolução CFE n ${ }^{\circ}$ 02/69 (BRASIL, 1969b), que se incumbiu de fixar o currículo mínimo e a duração do curso. Essa regulamentação manteve a formação de professores para o Ensino Normal e introduziu, oficialmente, as habilitações para formar os especialistas responsáveis pelo trabalho de planejamento, supervisão, administração e orientação, que constituíram, a partir de então, um forte meio de identificar o pedagogo. As habilitações foram amplamente difundidas, tornando-se nucleares para o curso ao longo de grande parte de sua trajetória.

Nessa perspectiva, os cursos de Pedagogia, que continuavam formando os técnicos de educação e os professores para as Escolas Normais, passam a ser, segundo Silva (1999), ao mesmo tempo, objeto de disputa para a formação do professor primário e objeto de crítica acerca da sua natureza e função.

Sabe-se que, em 1971, pela Lei de Diretrizes e Bases da Educação Nacional (LDBEN), a escola Normal passou a se chamar Habilitação Específica para o Magistério (HEM), e os profissionais por ela formados tinham o direito de lecionar de $1^{a}$ a $4^{a}$ série. Em 1986, o Conselho Federal de Educação criou uma resolução que permite, aos cursos de Pedagogia, formarem técnicos em Educação e ofertarem habilitação para que o profissional pudesse lecionar de $1^{\mathrm{a}} \mathrm{a}$ $4^{a}$ série. Nesse momento, abre-se uma nova porta para a formação inicial do professor das séries iniciais, que sai da responsabilidade apenas do Ensino do $2^{\circ}$ grau (nomenclatura utilizada a partir da Lei no 5692/71) para ser, também, responsabilidade do Ensino Superior.

Na década de 1980, receptor de inúmeras críticas, o curso de Pedagogia apontava a fragmentação de forte caráter tecnicista e a ênfase na divisão técnica do trabalho na escola.

Nesse período, foram intensos os movimentos pela reformulação dos cursos de formação dos profissionais da educação, levantando a bandeira de um curso de Pedagogia baseado na formação de professores para os anos iniciais do Ensino Fundamental.

No entanto, há que se ressaltar que o debate, sempre crescente, nunca foi consensual. Apesar de prevalecer a concepção que tem a docência como o núcleo forte da pedagogia, pelo menos duas outras tendências circulam no debate. Em síntese, segundo Kuenzer e Rodrigues 
(2007), as três concepções podem ser assim formuladas: pedagogia centrada na docência (licenciatura - professor); pedagogia centrada na ciência da educação (bacharelado - pedagogo); e pedagogia centrada nas duas dimensões, formando, integradamente, o professor e o pedagogo.

No entanto, observa-se que, desde 1985, o curso de Pedagogia tem oferecido uma gama de habilitações, o que tem possibilitado a estes profissionais atuarem em diversos espaços. Contemplando uma ação pedagógica múltipla, em que o pedagógico perpassa toda a sociedade, extrapolando o âmbito escolar formal, abrangendo esferas mais amplas da educação informal e não formal, criando formas de educação paralela, desfazendo praticamente todos os nós que separavam escola e sociedade. Porém, a formação específica para professores das séries iniciais fica em um nível menos privilegiado.

Com a aprovação da nova LDB, Lei no 9.394, em dezembro de 1996 (BRASIL, 1996), desencadearam-se, ainda mais, ações do Ministério da Educação (MEC) e do Conselho Nacional de Educação (CNE) no sentido de redefinir a formação do profissional do magistério, segundo as novas possibilidades colocadas pelo texto legal. A reforma para a formação de professores inscreveu-se nas reformas educacionais.

A partir de 1996, com a promulgação da nova LDB 9.394/96 (BRASIL, 1996), a responsabilidade pela formação inicial dos professores dos anos iniciais passou a ser feita, preferencialmente, nos cursos de Pedagogia. Algumas mudanças intermediárias aconteceram dentro desse período. Dessa forma, é possível referenciar passos marcantes desta trajetória.

A nova LDBEN 9.394/96 instituiu que era obrigatório o professor da Educação Básica ter nível Superior, estabelecendo no artigo 62:

A formação de docentes para atuar na educação básica far-se-á em nível superior, em curso de licenciatura, e graduação plena, em universidades e institutos superiores de educação, admitida, como formação mínima para o exercício do magistério na educação infantil e nas quatro primeiras séries do ensino fundamental, a oferecida em nível médio, na modalidade Normal. (BRASIL, 1996)

Conforme o Plano Nacional de Educação (BRASIL, 2001), em dez anos, todos os profissionais que atuavam na Educação Básica deveriam se adaptar à nova legislação. Com essa exigência, começa uma corrida contra o tempo para que todos os profissionais, que não tivessem curso Superior e que já estivessem em sala de aula, o fizessem. O que, de fato, não aconteceu, sendo que este prazo foi extinto pelo novo governo, pela Resolução do CNE/CEB $n^{\circ}$ 01/2003 de 20/08/2003 (BRASIL, 2003), pois havia muitos professores que não tinham conseguido buscar uma formação Superior conforme o prazo estabelecido.

A extinção dos cursos de magistério da rede pública de ensino, que ocorreu após 1996, não somente no Estado do Paraná, mas no país inteiro, fez com que as escolas privadas assumissem, cada vez mais, tais cursos de formação docente.

A partir da promulgação da LDB 9.394/96 (BRASIL, 1996), um número nunca antes produzido de leis, regulamentações, decretos, resoluções e pareceres foi definindo, formatando, disciplinando, controlando e desonerando o Estado da formação de professores, acentuando, gravemente, a fragilização desta formação, agora entregue, em sua maioria, à iniciativa do empresariado, e conformada, portanto, à obtenção do lucro. 
Almeida, M. B.; Lima, M. G.

Freitas (2002, p. 148) faz uma análise deste percurso:

Todo esse processo tem se configurado como um precário processo de certificação e/ou diplomação e não qualificação e formação docente para o aprimoramento das condições do exercício profissional. A formação em serviço da imensa maioria dos professores passa a ser vista como lucrativo negócio nas mãos do setor privado e não como política pública de responsabilidade do Estado e dos poderes públicos. O 'aligeiramento' da formação inicial dos professores em exercício começa a ser operacionalizado, na medida em que tal formação passa a ser autorizada fora dos cursos de licenciatura plena como até então ocorria e como estabelece o art. 62 da LDB. Vivemos, portanto, ao contrário do que prega o discurso oficial, um processo de 'desprofissionalização' do magistério.

Após a LDB 9.394/96, determinou-se a criação de Diretrizes Curriculares Nacionais (DCN) para os cursos de graduação e a formação docente em nível Superior. Todos os cursos de graduação tiveram suas DCN's definidas, com exceção do curso de Pedagogia que, apesar de algumas tentativas junto ao Conselho Nacional de Educação (CNE), só em maio de 2006 teve uma Resolução aprovada.

Pode-se analisar que as Diretrizes Curriculares Nacionais para o Curso de Pedagogia (DCNP) expressam, de acordo com Triches (2007), uma correlação de forças entre projetos distintos e antagônicos para a reformulação do curso de Pedagogia.

De acordo com as DCNP (BRASIL, 2006), o curso de Pedagogia passa a ser exclusivamente uma licenciatura, que formará docentes para atuarem na educação infantil (EI) e anos iniciais do Ensino Fundamental (AIEF). Essas duas modalidades não se farão por opção das instituições de ensino por uma ou outra e, sim, pelas duas. Além dessas, o curso também formará docentes para o Ensino Médio na modalidade Normal (EMN) (antigo curso de magistério) e para outros cursos de Educação Profissional (EP) voltados para a educação. Ou seja, de início, o formado neste curso será docente (entendido como sinônimo de professor) para quatro modalidades diferentes.

Após a constatação do conteúdo do artigo $4^{\circ}$ da resolução CNE/CPD nº 1 (BRASIL, 2006), incluem-se mais dois setores de atuação (gestão e produção de conhecimento) às quatro modalidades deste licenciado apontadas anteriormente (EI, AIEF, EMN, EP). Atingindo, até aqui, seis campos de ação que não acabam por aí, pois, no artigo $8^{\circ}$, item IV (BRASIL, 2006, p. 5) da mesma resolução, é incluída a modalidade de Jovens e Adultos para o estágio curricular obrigatório.

Enfim, esse docente formado num curso de Pedagogia de, no mínimo, 3.200 horas, conforme apontam as DCNP (BRASIL, 2006) e sem previsão de duração mínima em anos, passa a ter, no mínimo, oito possibilidades de atuações diferentes. Reforça-se que tudo isso em um único curso.

Muitos desafios deverão ser superados pelo curso de Pedagogia, entre eles o desafio da definição dos componentes de conteúdos necessários para abranger a imensa formação proposta. 
Formação inicial de professores e o curso de Pedagogia: ...

Com toda essa imensa bagagem de conteúdos pretendida para o curso de Pedagogia, o que pensar, então, em termos de conteúdos matemáticos para as séries iniciais, visto que o curso traz uma gama enorme de saberes?

Curi (2005) aponta que, em relação aos conteúdos matemáticos presentes nos cursos de Pedagogia, não há uniformidade (base comum) e nem ao menos apontamentos legais que direcionem o tratamento que deverá ser dado ao trabalho com os saberes disciplinares de matemática para as séries iniciais do Ensino Fundamental.

O conhecimento adquirido sobre a organização do curso de Pedagogia evidenciou que as reformas, pareceres, regulamentações, estabelecimentos de grades curriculares e a definição das disciplinas e seus conteúdos não foram suficientes para resolver os dilemas enfrentados ao longo dos anos em torno das especificidades do curso de Pedagogia; das questões entre bacharelado e licenciatura, e dos esforços dos educadores no sentido de definirem sua identidade.

Com muitas imprecisões, não é surpreendente identificar que os conteúdos que fazem parte do conhecimento da matemática estão relegados a um segundo plano na formação do pedagogo; as horas tomadas com o grande número de habilitações oferecidas não comportam a organização necessária para a formação do professor, ou seja, do conhecimento das áreas específicas.

\section{Formação de professores e os conhecimentos necessários para ensinar matemática}

No atual modelo de educação, o processo de aprendizagem da matemática, em seu aspecto formal e sistematizado, inicia-se na Educação Básica nos primeiros anos do Ensino Fundamental, do primeiro ao quarto ano de escolarização dos alunos, onde são construídas as bases para a formação matemática. Nessas séries, em geral, tem-se, como professores de todas as áreas do conhecimento, os pedagogos, que são profissionais graduados em cursos de Licenciatura em Pedagogia.

São esses profissionais que iniciam o processo de alfabetização de estudantes das séries iniciais. Dessa forma, torna-se necessário que o pedagogo tenha uma formação que o possibilite, pedagógico-didaticamente, desenvolver conhecimentos sólidos e eficazes, capazes de garantir aprendizagens minimamente satisfatórias quanto às áreas de conhecimento em que atua.

O curso de Pedagogia possui um currículo que abrange uma formação geral caracterizada pelas Didáticas, Psicologias, Sociologias, Filosofias, entre outras, e a formação específica em determinadas áreas do conhecimento, relacionadas ao processo de aprendizagem dos alunos das séries iniciais, como é o caso da Matemática, História, Geografia, Português, entre outras.

Em decorrência do objetivo de formar um professor para ensinar matemática nos anos iniciais do Ensino Fundamental, é preciso garantir espaços para uma formação que contemple os conhecimentos matemáticos abordados nos anos iniciais da escolaridade básica, preferencialmente, numa perspectiva que inclua questões de ordem didática e curriculares, mas deve orientar-se por, e ir além daquilo que os professores irão ensinar nas diferentes etapas da escolaridade. 
Segundo Ponte (2002), os conhecimentos do professor sobre os objetos de ensino devem incluir os conceitos das áreas de ensino definidos para a escolaridade na qual ele irá atuar, tanto no que se refere à profundidade desses conceitos como à sua historicidade, sua articulação com outros conhecimentos e o tratamento didático, ampliando, assim, seu conhecimento da área.

Shulman (1986) trouxe importantes contribuições para o estudo dos conhecimentos profissionais que os professores devem possuir e que fundamentam sua prática. As investigações que esse autor realizou permitiram que ele identificasse três vertentes no conhecimento necessário ao professor: o conhecimento do conteúdo da disciplina, o conhecimento didático do conteúdo da disciplina e o conhecimento do currículo.

O conhecimento do conteúdo da disciplina deve envolver o conhecimento para ensinar, ou seja, o professor deve saber, e muito bem inclusive, o conteúdo que vai ensinar: conhecimentos relativos à natureza e aos significados dos conteúdos, o desenvolvimento histórico, os diversos modos de organizá-los.

Já o conhecimento didático do conteúdo, apresenta uma combinação entre o conhecimento da matéria e o conhecimento do modo de como ensiná-la. O conhecimento didático do conteúdo, ou o conhecimento de conteúdo pedagógico, compreende “[...] as formas mais úteis de representação de idéias, as analogias mais importantes, ilustrações, exemplos, explicações e demonstrações, a forma de representar e formular a matéria para torná-la compreensível [...]" (SHULMAN, 1986, p. 9).

O professor necessita, segundo Pires (2002), ter conhecimentos relativos aos conteúdos matemáticos e à natureza da matemática, de modo a sentir-se à vontade quando a ensina; ser capaz de relacionar ideias particulares ou procedimentos dentro da matemática, de conversar sobre ela e de explicar os juízos feitos e os significados e razões para certas relações e procedimentos. Para isso, o professor precisa ter uma compreensão profunda da matemática, da sua natureza e da sua história, do papel que esta tem na sociedade e na formação do indivíduo.

Entende-se, dessa forma, que o conteúdo específico de matemática continua sendo um importante instrumento de trabalho do professor na construção das habilidades e competências matemáticas requeridas pelo aluno e pela sociedade. Além disso, a não- aprendizagem dos conteúdos trabalhados nas séries iniciais do Ensino Fundamental tem grandes implicações ao longo de toda a vida escolar do aluno, podendo comprometer o aprendizado do saber matemático trabalhado ao longo dos últimos anos do Ensino Fundamental e do Ensino Médio.

Ao defender a importância da formação no conteúdo específico (o que ensinar) e a sua íntima articulação com o conteúdo pedagógico (como ensinar), considera-se que a licenciatura não pode abrir mão de discutir por que ensinar e para quem ensinar.

É preciso trabalhar conteúdo com os professores e futuros professores? Sim, pois o professor é o transmissor do saber socialmente acumulado. É preciso trabalhar atitudes? Sim, pois elas definem a disposição das pessoas para o aprendizado da matemática. Mas também é preciso trabalhar a ideologia, pois ela situa o professor em discussões mais abrangentes que influenciam a sala de aula. (SZTAJN, 1997, p. 202) 
Somente articulando esses elementos (o que ensinar, como ensinar, por que ensinar e para quem ensinar), a licenciatura dará, ao futuro professor, as condições mínimas necessárias para que ele desenvolva um trabalho com os saberes matemáticos que esteja em sintonia com as novas demandas que a sociedade vem exigindo da educação escolar.

Ao se ressaltar a questão do conteúdo específico, deseja-se evidenciar que “[...] a competência básica de todo e qualquer professor é o domínio do conteúdo específico. Somente a partir deste ponto é possível construir a competência pedagógica [...]" (CANDAU, 1997, p. 46).

A consideração a respeito das especificidades do conhecimento matemático com as quais o professor vai trabalhar é, segundo Curi (2005), um desafio para os programas de formações de professores. As investigações sobre o conhecimento matemático nas três vertentes apontadas por Shulman (1986) devem exercer uma forte influência, sobretudo pelo fato de os cursos de formação de professores (pedagogos) em nosso país não conferirem, segundo Curi (2005), destaque aos conhecimentos referentes às áreas de conhecimento

A conotação dada aos conteúdos da Educação Básica, segundo Pires (2002), não deve ser tratada apenas como revisão, pois isto acaba causando desinteresse por parte dos futuros professores. Para a autora, faz-se necessário construir conhecimento aprofundado e consistente para a ampliação do universo de conhecimentos matemáticos em relação a outras disciplinas, e adaptá-las às atividades escolares próprias das diferentes etapas do Ensino Fundamental.

Pires (2002) destaca, ainda, que os cursos de formação de professores de matemática devem dar um tratamento especial aos conteúdos matemáticos, com ênfase no processo de construção desses conhecimentos, sua origem, seu desenvolvimento de forma articulada com sua didática, para que os futuros professores possam consolidar e ampliar os conteúdos com os quais trabalharão no Ensino Básico.

Considerando as ideias desses autores, é certamente consensual a concepção de que qualquer professor de matemática deve saber mais matemática do que aquela que se vai ensinar. Para isso, a formação inicial do professor deverá providenciar uma compreensão profunda da matemática com a qual irá trabalhar em sua prática educativa.

Com base nas ideias descritas, acredita-se que a competência básica de todo e qualquer professor é o domínio do conteúdo específico, haja vista que o conteúdo específico de matemática continua sendo um importante instrumento de trabalho do professor na construção das habilidades e competências matemáticas requeridas pelo aluno e pela sociedade. Somente a partir deste domínio é possível construir a competência pedagógica.

Ao defender a importância da formação no conteúdo específico (o que ensinar) e a sua íntima articulação com o conteúdo pedagógico (como ensinar), consideramos que a licenciatura não pode abrir mão de discutir por que ensinar e para quem ensinar. Somente articulando esses elementos (o que ensinar, como ensinar, por que ensinar e para quem ensinar), a licenciatura dará, ao futuro professor, as condições mínimas necessárias para que ele desenvolva um trabalho com os saberes matemáticos que esteja em sintonia com as novas demandas que a sociedade vem exigindo da educação escolar. 
Almeida, M. B.; Lima, M. G.

\section{Metodologia}

Tomando como base essas discussões sobre a formação inicial de professores, desejase acrescentar a seguinte questão: A formação inicial de professores ofertada no curso de Pedagogia prepara adequadamente os futuros docentes para trabalharem com os conteúdos disciplinares de matemática?

Nesta direção, este trabalho teve como objetivos:

a) Analisar como vem se dando a formação inicial dos docentes, realizada pelo curso de Pedagogia, para o trabalho com os conteúdos disciplinares de matemática nas séries iniciais do Ensino Fundamental;

b) Saber como os alunos que estão concluindo o curso de Pedagogia avaliam as contribuições da formação inicial para o trabalho com a matemática em sua prática educativa.

Para isso, é tomada como objeto de análise a formação inicial de professores, em especial, a formação matemática ofertada pelo curso de Pedagogia em uma universidade pública do estado do Paraná.

A metodologia utilizada privilegia a pesquisa qualitativa composta, inicialmente, por dois tipos de análise: bibliográfica e documental.

O estudo bibliográfico referiu-se ao tema formação de professores, em especial ao curso de pedagogia e formação inicial matemática para atuar nas séries iniciais do Ensino Fundamental, na busca de referenciais teóricos que pudessem nortear a análise dos dados coletados na pesquisa.

A análise documental tornou-se indispensável, no momento em que se definiu abordar a formação inicial de docentes das Séries Iniciais do Ensino Fundamental como o componente a ser estudado. Isso implicou a leitura de arquivos oficiais - leis, diretrizes, pareceres, resoluções - e arquivos escolares - projeto político-pedagógico do curso e plano de ensino (ementa). As informações obtidas dessas leituras foram sintetizadas na forma de fichamentos que continham anotações das reflexões realizadas à luz do referencial teórico. Com essa análise, procuram-se aprofundar os conhecimentos acerca dos parâmetros que orientam os cursos de licenciatura, das competências e habilidades que fundamentam a formação docente.

A análise documental teve foco nos Pareceres e Resoluções do Conselho Nacional de Educação do Ministério da Educação (MEC), nos decretos e nas diretrizes curriculares do Curso de Pedagogia, nas diretrizes específicas das áreas de formação de professores para a Educação Básica e no Projeto Pedagógico do curso de Pedagogia analisado. Todos os documentos foram encontrados no site do MEC e nas obras de autores que tratam do assunto; os demais documentos foram disponibilizados no site da instituição em lide.

Para a pesquisa de campo, optou-se pela utilização dos seguintes instrumentos: questionário misto e ficha contendo problemas para serem resolvidos. Neste artigo, utilizaremos, para análise dos dados, apenas o questionário.

A característica acessível do questionário foi uma das razões pela qual se usou essa técnica para a coleta de informações sobre o grupo discente. Segundo Fachin (1993, p. 121), "O questionário consiste num elenco de questões que são apreciadas e submetidas a certo número de pessoas com o intuito de obter respostas para a coleta de informações". A acessibilidade, a garantia do anonimato, a uniformidade das questões são algumas das vantagens apontadas pela autora. 
A outra razão pela opção ao questionário deveu-se à possibilidade de rapidez no retorno das respostas e à maior facilidade para se contatarem os futuros professores, visto que eles dispõem de pouco tempo para atendimento aos pesquisadores.

Para análise dos dados coletados a partir do questionário, procedeu-se da seguinte forma: as questões fechadas foram tabuladas, calculando-se o percentual das respostas.

Para sistematização e análise dos dados contidos no questionário, referentes às questões abertas, pautou-se na análise de conteúdo (BARDIN, 1979). Esta opção foi feita porque, após a leitura de todas as respostas referentes a cada questão, percebeu-se que as mesmas atendiam às especificidades para categorização das respostas.

As questões abertas foram classificadas em categorias que, conforme orientação de Bardin (1979), emergiram da análise das respostas dos alunos, que foram agrupadas de acordo com frases ou palavras que tinham em comum para que fossem analisadas à luz da literatura sobre formação de professores de matemática.

A análise de conteúdo de Bardin (1979) é um conjunto de técnicas de análise de comunicação que utiliza procedimentos sistemáticos e objetivos de descrição do conteúdo das mensagens, a qual permitiu confrontar, metodologicamente, a verificação e interpretação dos significados das mensagens (manifestos ou subjacentes) presentes nas respostas dos participantes. Segundo a autora, a categorização tem como primeiro objetivo fornecer, por condensação, uma representação simplificada dos dados brutos. As inferências finais são efetuadas a partir do material reconstruído. Através das relações entre as categorias, e de suas interpretações, é possível desenvolver explicações e afirmativas (proposições).

Para os objetivos deste trabalho, verificou-se a frequência das respostas e procurou-se relacionar as variáveis, de forma que fosse possível prosseguir com uma análise qualitativa dos dados.

Nos depoimentos coletados, foram identificadas as expressões-chave, as ideias centrais e a recorrência de respostas semelhantes, sendo que a análise de conteúdo (BARDIN, 1979) possibilitou organizar os dados em categorias quantificáveis. O critério de categorização adotado foi o semântico, por categorias temáticas, de acordo com seus significados, a partir das significações que a mensagem fornece.

Os dados obtidos foram categorizados de acordo com a análise de conteúdo de (BARDIN, 1979), organizados em tabelas, descritos e analisados com base no referencial teórico de pesquisadores que estudam a formação do professor que ensina matemática nos anos iniciais.

Foram sujeitos dessa pesquisa os alunos da única turma do $4^{\circ}$ ano (concluintes) do curso de Pedagogia (ano 2008), de uma Universidade Estadual localizada no Centro-Oeste do Paraná.

\section{Análise dos resultados}

A formação inicial do curso de Pedagogia investigado está voltada para a formação de pedagogos com habilitação para atuação em escolas de Educação Infantil, Educação Básica, Educação Superior e Gestão Escolar. Além das escolas, os pedagogos também são requisitados em: empresas públicas e privadas, clínicas psicopedagógicas, pesquisa educacional, escritórios de assessoria pedagógica e educacional, na indústria de artefatos e brinquedos 
educativos e em programas de rádio e televisão educativos. Por isso, são abordadas, durante o curso, disciplinas que tratam da formação do pedagogo para espaços não escolares, como podemos citar a disciplina de Estágio Supervisionado em Gestão de Instituições Escolares e não escolares.

No projeto do curso, declara-se a intenção de tomar como referência as Diretrizes Curriculares Nacionais para o Curso de Graduação em Pedagogia (DCNP) e as Diretrizes Curriculares Nacionais para Formação de Professores da Educação Básica (DCN), em nível Superior, bem como outros dispositivos legais que se referem ao curso de Pedagogia e aos cursos de Ensino Superior, no que diz respeito às licenciaturas.

Observa-se que a questão do domínio de conteúdos não aparece em nenhum dos objetivos do curso, evidenciando que, se as Diretrizes Curriculares do Curso de Pedagogia não deixam claro isto, o projeto dessa instituição também falha neste aspecto.

O que foi identificado por meio da organização curricular do curso vai ao encontro da análise de Curi (2005), que verificou que os cursos de graduação em Pedagogia elegem as questões metodológicas como essenciais à formação de professores, sendo que isto não garante uma formação adequada em termos de conhecimentos para se ensinar matemática na Educação Infantil e nas séries iniciais do Ensino Fundamental.

O curso de graduação em Pedagogia deveria propiciar a instrumentação pedagógica específica para a docência, mas também favorecer a necessária formação teórica do pedagogo. Porém, isto não está acontecendo, mediante análise do Projeto Político Pedagógico do curso.

A única disciplina destinada à matemática é oferecida em quatro aulas durante o segundo semestre do terceiro ano do curso, totalizando apenas 68 horas. Em um curso de Pedagogia, cujos Componentes Curriculares são compostos de uma carga horária equivalente a 3.392 horas, 68 horas equivalem, meramente, a 2\% de toda a formação inicial.

Considerando-se a ementa e a programação propostas para a disciplina de Metodologia do ensino da matemática e o número de horas destinadas a essa disciplina, evidencia-se que essa formação é muito inexpressiva, e não atinge as três vertentes do conhecimento do professor destacadas por Shulman (1986): o conhecimento do conteúdo, o conhecimento didático do conteúdo e o conhecimento curricular, bem como as demais categorizações realizadas por Gauthier (1998), Ponte (2002) e Tardif (2002).

Küenzer e Rodrigues (2007) entendem que, da maneira como o curso de Pedagogia está organizado, representa uma totalidade vazia. Para as autoras, é impossível o curso dar conta de uma formação de qualidade com um perfil demasiadamente ampliado, que prevê a formação de um profissional para atuar nas diversas áreas da docência, na gestão e na produção de conhecimento.

Analisando as DCNP (BRASIL, 2006) e o Projeto Político Pedagógico do curso, concorda-se com Libâneo (2002), quando este afirma que é uma incongruência formar em 3.200 horas, num mesmo curso, três ou quatro profissionais.

Para Curi (2005), os conhecimentos constituídos pelo futuro professor em sua trajetória pré-profissional vão influenciar sua ação docente. Serrazina (2002) considera como fatores que influenciam a forma como os professores das séries iniciais encaram o ensino da matemática: o conhecimento da matemática, o interesse e o gosto por ensinar matemática. No entanto, as informações levantadas por meio do questionário expressaram, em sua maioria, esta relação com o conhecimento matemático: 
$\mathrm{A}_{10}$ : Nunca tive um bom relacionamento com a matemática.

$\mathrm{A}_{17}$ : Nunca consegui aprender matemática. Para mim ela é muito difícil.

$\mathrm{A}_{20}:$ A Matemática sempre foi pra mim um bicho de sete cabeças.

$\mathrm{A}_{25}$ : Não sou nenbum pouco fã da matemática.

Considerando, por meio de dados levantados, que a maioria destes alunos nunca trabalhou como professor, seria preciso, segundo Curi (2005), a reflexão sobre as formas de constituição dos conhecimentos do professor nessa etapa de sua trajetória profissional.

Ou seja, os cursos de graduação em Pedagogia deveriam pensar formas de atender a este público que está acessando os cursos de Pedagogia, sem a atuação profissional no Ensino Normal Médio. E mais grave, sem saber conhecimentos básicos sobre matemática.

Estes depoimentos alertam que, nos cursos de formação inicial de professores, é possível proporcionar legalmente, ao futuro professor, a aquisição de uma das polivalências, como, por exemplo, a de matemática, sem que seja, efetivamente, removido o muro de desafeto que os distancia desta área de conhecimento.

A relação com o conhecimento matemático deve ser libertadora do medo gerado pelo desconhecimento, e não, exatamente, o contrário, como podemos observar nos depoimentos desses alunos. O agravante diante dessas revelações é que esses graduandos do curso de Pedagogia iniciam ou vão iniciar a criança num conhecimento pelo qual eles têm desafeto ou indiferença.

O pressuposto básico que move o empenho que se tem com esta questão da formação inicial de professores é o de que esses concluintes do curso de Pedagogia são ou serão professores de matemática, portanto, precisam estabelecer um relacionamento com esta área de conhecimento que os satisfaça. Sem que isto ocorra, é provável que estejam desenvolvendo, nas crianças, os mesmos bloqueios que tiveram quando aprenderam matemática.

Nota-se que vários dos conteúdos citados pelos graduandos, com os quais eles apresentam dificuldades, fazem parte do currículo do Ensino Fundamental das séries iniciais. Sobre este aspecto, Torres (1998 apud MAKAREWICZ, 2007, p. 23) enfatiza que:

A aprendizagem dos professores não começa no primeiro dia de sua formação como professor, começa em sua infância, no lar e quando esse futuro professor vai para a escola. O mau sistema escolar forma não só maus alunos, como maus professores que, por sua vez, reproduzirão o círculo vicioso e empobrecerão cada vez mais a educação.

Logo, em se tratando de formação inicial, tema da pesquisa, a experiência que o estudante tem com relação ao ensino de matemática é, em grande parte, aquela decorrente de sua vivência como aluno da Educação Básica.

Tardif (2002) considera que os conhecimentos profissionais do professor são provenientes, também: de sua cultura pessoal, de sua história de vida e de sua escolaridade anterior, e do seu próprio saber proveniente de experiências profissionais. O processo pessoal de aprendizagem profissional da docência também tem sido identificado por Tardif como componente do conhecimento profissional do professor.

Ponte (2002) enfatiza que o professor, para ensinar matemática, deve ter uma boa relação com a matemática que vai lecionar. 
Talvez seja urgente a necessidade de se pensar na formação inicial do professor, em processos que lhes permitam um convívio de reaproximação com a matemática. Serrazina (2005, p. 307) afirma que:

[...] quando os futuros professores chegam à sua formação inicial possuem um modelo implícito, um conhecimento dos conteúdos matemáticos que têm de ensinar, adquiridos durante a sua escolarização, bem como um conhecimento didático vivido durante a sua experiência como alunos.

Tendo em vista os apontamentos de Tardif (2002), Ponte (2002) e Serrazina (2005), a formação inicial de professores deve favorecer o desenvolvimento de concepções, sentimentos, atitudes e capacidades positivas em relação à matemática, até para ajudá-los a superarem os problemas anteriores. Essa formação deve encorajar os futuros professores a refletirem, questionando seus conhecimentos e dificuldades, de forma que possam vir a alterá-las.

Entretanto, após ter passado pelo curso de Pedagogia, a maioria dos graduandos continua não gostando de matemática: acham difícil, apesar de a encararem como necessária e importante para a vida. Os graduandos pesquisados comentaram que:

\section{$\mathrm{A}_{21}$ : Continuo tendo dificuldades e não gosto da disciplina. \\ $\mathrm{A}_{17}$ : Continuo não gostando. Não me identifico com a disciplina. \\ $\mathrm{A}_{03}$ : Continuo não gostando, mas tenho plena consciência de que é necessária para minha formação.}

Em relação a esse aspecto, Gómez Chacón (2002) distingue duas categorias de atitudes em relação à matemática: atitude sobre a matemática e atitude matemática. As atitudes sobre a matemática dizem respeito à valorização e apreciação desta disciplina e ao interesse por ela e por sua aprendizagem. Nesse caso, predomina o aspecto afetivo mais do que o cognitvo, e manifesta-se através de interesse, satisfação, curiosidade, valorização.

Levando em consideração os apontamentos de Gómez Chacon (2002), verifica-se que os graduandos não manifestaram interesse em relação aos conhecimentos matemáticos, devido às suas atitudes sobre a matemática, mesmo nesta etapa da formação; além disso, podemos auferir que a graduação em Pedagogia não os auxiliou neste aspecto afetivo em relação à matemática, o que poderá ter consequências negativas para o processo de ensino e aprendizagem desta disciplina.

Considerando a representação negativa da matemática presente nos graduandos pesquisados, acredita-se ser necessário que o curso de Pedagogia mude esta situação e evite que os futuros professores voltem a ensinar uma nova geração a detestar a matemática, assim como eles detestaram durante sua passagem pela Educação Básica. Por isso, é fundamental que o curso de Pedagogia, ora analisado, redimensione sua maneira de trabalhar a formação matemática desses futuros professores.

Segundo Ponte (2002), quando o tema da formação matemática inicial de professores é colocado em discussão, existe uma predominância na abordagem da questão do ponto de vista didático-metodológico; o conhecimento da matemática fundamental sempre fica relegado a segundo plano. E foi isso que se verificou estar acontecendo neste curso. 
As informações revelaram que o conhecimento matemático não foi trabalhado e aprofundado de modo a permitir uma aprendizagem significativa dele, e que os graduandos pesquisados sentem, em sua formação, a falta desse conteúdo.

As necessidades apontadas pelos futuros professores vêm ao encontro do que propõem as pesquisas e os documentos normativos que tratam da formação de professores para este nível de escolaridade; entretanto, parece que estas necessidades não estão sendo sentidas, percebidas, muito menos entendidas e praticadas pelo curso de Pedagogia, não só neste curso analisado, mas nos demais cursos de Pedagogia em nível nacional, como apontam Gatti e Nunes (2008).

Por isso, mediante os dados levantados, pode-se constatar que o curso de Pedagogia investigado ainda não conseguiu articular adequadamente a relação entre os conhecimentos específicos da matemática e os conhecimentos pedagógicos. Haja vista que, para a maioria dos graduandos pesquisados, o curso de Pedagogia não atendeu as expectativas em relação à matemática e ao seu ensino.

As reclamações giram em torno do pouco contato e aprofundamento do conhecimento matemático necessário para a formação dos professores que atuarão nas séries iniciais.

Alguns depoimentos podem ilustrar melhor estes dados.

$$
\begin{aligned}
& \mathrm{A}_{10} \text { : Não conseguiu, é muito superficial. } \\
& \mathrm{A}_{26}: \text { Deixou a desejar quanto a conteúdos específicos pois na verdade aprendemos } \\
& \text { apenas as metodologias de como ensinar mas não aprendemos o que ensinar. } \\
& \mathrm{A}_{05}: \text { O ensino da matemática teria que ser uma matéria que fosse estudada de } \\
& \text { maneira detalhada e não superficial, porque muitos de nós temos dificuldades nesta } \\
& \text { disciplina. } \\
& \mathrm{A}_{17}: \text { Dentro de Pedagogia tem-se aprendido com relação a Educação como um } \\
& \text { todo, porém com relação à matemática, infelizenente praticamente nada. } \\
& \mathrm{A}_{10}: \text { Aprendi a usar os jogos, mas não aprendi como aplicar os conteúdos. }
\end{aligned}
$$

Por meio dos dados coletados e analisados, verificou-se que a forma como o curso de Pedagogia vem abordando os conteúdos e metodologias referentes à matemática e ao seu ensino está imprimindo, nesses futuros professores, uma identidade pedagógica esvaziada de conteúdos, sendo que se aprende a prática do ensino, mas não o momento de seu uso. Haja vista que a preparação, como foi constatada, se reduz a um conhecimento pedagógico abstrato, porque é esvaziado do conteúdo a ser ensinado. Isso se revelou claramente nos depoimentos dos alunos concluintes do curso.

Outro fator que merece destaque é o número de disciplinas destinadas ao ensino de matemática - apenas uma, em apenas um semestre, que, segundo os alunos pesquisados, é insuficiente, diante das necessidades reais de uma formação que atenda às novas demandas educacionais para um ensino de matemática com qualidade:

Uma das críticas mais freqüentes aos cursos de formação de professores é a desarticulação quase total entre conhecimentos específicos e conhecimentos pedagógicos. Nos cursos de formação de professores polivalentes, a crítica que pode ser feita é a da ausência de conhecimentos específicos relativos às diferentes áreas do conhecimento com as quais o futuro professor irá trabalhar. (CURI, 2005, p. 160) 
Almeida, M. B.; Lima, M. G.

As análises dos depoimentos vêm indicar que há um conhecimento a ser construído pelos futuros professores, que é mais do que mera justaposição do aspecto de conteúdo e do aspecto pedagógico.

As observações giram em torno da superficialidade na abordagem do conhecimento matemático e no pouco tempo disponível para a aprendizagem desse conhecimento. inicial:

Vejamos algumas respostas dos graduandos em relação ao processo da formação

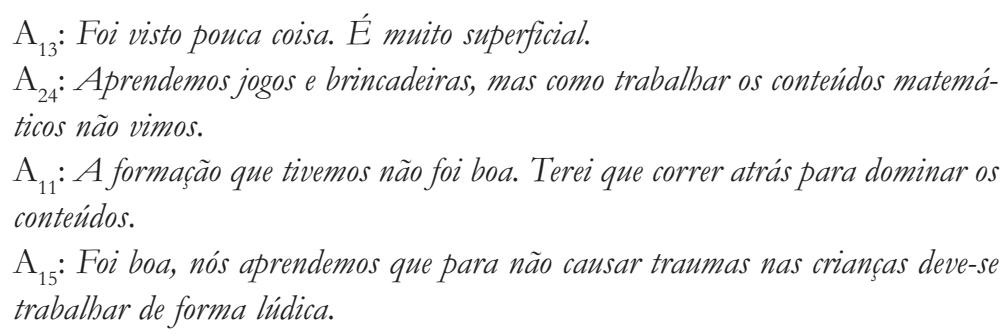

Como se pode observar, muitos graduandos pesquisados afirmam que o curso poderia ter aprofundado mais os conteúdos matemáticos; e aqueles que acreditam que o curso ajudou, reportam-se ao aspecto lúdico da aprendizagem matemática. Observamos ainda, pelos depoimentos dos egressos do curso, que essa disciplina também não conseguiu articular os conteúdos matemáticos e os conhecimentos didáticos.

Há graduandos que percebem a necessidade de buscarem um aprofundamento maior dos conteúdos matemáticos quando forem lecionar, entretanto, não se pode negar a responsabilidade ímpar que a Instituição de formação deve exercer quanto à formação básica do professor das séries iniciais do Ensino Fundamental.

Segundo Mello (2000, p. 98):

[...] ninguém facilita o desenvolvimento daquilo que não teve oportunidade de aprimorar em si mesmo. Ninguém promove a aprendizagem daquilo que não domina, é preciso que o professor experimente, enquanto aluno aquilo que ele deverá ensinar a seus próprios alunos [...].

Ao se ressaltar o número reduzido de disciplina oferecida pelo curso de Pedagogia para o trabalho com o ensino de matemática, não se deseja defender a construção de um currículo baseado no modelo da racionalidade técnica, pois esse modelo considera que, para ser bom professor, basta o domínio da área do conhecimento específico que se vai ensinar. Embora o conhecimento do conteúdo específico seja necessário ao ensino, simplesmente dominar tal conhecimento não garante que o mesmo seja ensinado e aprendido com sucesso.

Desse modo, deseja-se deixar claro que não é suficiente acrescentar, ao currículo dos cursos de Pedagogia, disciplinas que se limitem a abordar os saberes disciplinares de matemática. É fundamental que essas disciplinas procurem promover uma integração entre os saberes disciplinares de matemática e os saberes pedagógicos necessários ao trabalho com esses conteúdos nas séries iniciais do Ensino Fundamental. 


\section{Considerações finais}

Recorrendo-se às questões de investigação realizadas por meio do questionário, percebe-se que a formação matemática recebeu um espaço mínimo e insuficiente na formação inicial dos Pedagogos (futuros professores das séries iniciais). A desvalorização desta área do conhecimento pode trazer prejuízos para a formação matemática, não somente dos futuros professores, mas, sobretudo, para seus alunos das séries iniciais.

Por isso, reafirma-se que o tempo destinado ao tema matemática na formação de professores do curso de Pedagogia analisado precisa ser ampliado, e se considerar importante que esse futuro professor amplie seus conhecimentos sobre a Matemática como área de conhecimento, e não a veja apenas como mais uma das disciplinas do currículo escolar que terá de lecionar.

De acordo com análise dos depoimentos dos concluintes do curso de Pedagogia, praticamente não houve abordagens para explorar noções sobre como as crianças desenvolvem as suas estruturas lógico-matemáticas. Esta carência na formação dos Pedagogos provavelmente dificultará a sua compreensão sobre o fazer matemática das crianças e efetivar a aprendizagem matemática delas no cotidiano escolar.

Pode-se constatar, também, que o curso de Pedagogia dá prioridade às metodologias a serem utilizadas em sala de aula, em detrimento de uma abordagem mais profunda dos conteúdos de matemática que serão trabalhados pelos professores na sua futura prática educativa. O domínio de novas estratégias de ensino é fundamental para a construção de aprendizagens significativas, bem como na superação das dificuldades apresentadas por alunos com deficiências de aprendizagem. Mas como esses professores poderão adotar essas metodologias de ensino sem conhecerem os conteúdos que irão ensinar?

Dessa forma, o curso de Pedagogia imprime a esse profissional, conforme aponta Mello (2000), uma identidade pedagógica esvaziada de conteúdos, sendo que se aprende a prática do ensino, mas não a sua substância, pois a preparação se reduz a um conhecimento pedagógico abstrato porque é esvaziado do conteúdo a ser ensinado.

Não se deseja concluir este trabalho prescrevendo receitas que poderiam resolver os problemas inerentes à formação inicial do professor que atua nas séries iniciais do Ensino Fundamental - cujos reflexos se fazem presentes na qualidade do ensino de matemática, e vem à tona nas avaliações de desempenho desenvolvidas pelo MEC -, mas, apresentar algumas questões, cuja reflexão pode auxiliar os responsáveis pelo curso de Pedagogia a encontrarem um caminho para melhorar à formação inicial do professor para o trabalho com os conteúdos disciplinares de matemática.

Tem-se clareza de que a formação inicial é apenas a base da formação do professor, entretanto, torna-se imprescindível que a formação inicial possibilite, ao futuro professor, uma apropriação consistente dos diversos saberes necessários a sua prática profissional, o que, certamente, será um passo fundamental para a superação das deficiências que, há muito tempo, vêm se fazendo presentes no ensino de matemática.

O estudo dos concluintes do curso de Pedagogia configura-se como uma questão relevante para as pesquisas no campo da educação matemática, e que deve ser intensificada. Tendo em vista os resultados obtidos neste trabalho, não se pode ignorar que repensar o modelo de formação do professor é um passo indispensável para a melhoria da qualidade do ensino de forma geral, e para o ensino da matemática, em particular. 
Almeida, M. B.; Lima, M. G.

\section{Referências}

BARDIN, L. Análise de conteúdo. Lisboa: Edições 70, 1979.

BRASIL. Ministério da Educação. Parecer n. 252, de 11 de abril de 1969. Fixa os mínimos de conteúdos e duração a serem observados na organização do curso de Pedagogia.

Documenta, Rio de Janeiro, n. 1000, p. 101-117, 1969a.

Ministério da Educação. Resolução CFE nº. 2/69, de 12 de maio de 1969.

Reformula o curso de Pedagogia e propõe habilitações no último ano. Diário Oficial da

União, Brasília, 12 maio 1969b.

Presidência da República. Lei $\mathbf{n}^{\circ}$ 10172, de 09 de janeiro de 2001. Aprova o Plano Nacional de Educação e dá outras providências. Brasília, 2001. Disponível em: <https://www.planalto.gov.br/ccivil_03/leis/leis_2001/110172.htm>. Acesso em: 15 dez. 2007.

Ministério da Educação. Resolução do CNE/CEB 01, de 20 de agosto de 2003. Dispõe sobre os direitos dos profissionais da educação com formação de nível médio, na modalidade Normal, em relação à prerrogativa do exercício da docência, em vista do disposto na lei 9394/96, e dá outras providências. Diário Oficial da União, Brasília, 22 ago. 2003. Seção I, p. 12. Disponível em: < http://portal.mec.gov.br/cne/arquivos/pdf/ rceb01_03.pdf>. Acesso em: 30 mar. 2008.

Ministério da Educação. Resolução CNE/CP no 1, de 15 de maio de 2006. Institui Diretrizes Curriculares Nacionais para o curso de graduação em Pedagogia, licenciatura. Diário Oficial da União, Brasília, 16 maio 2006. Seção I, p. 11. Disponível em: <http:// portal.mec.gov.br/cne/arquivos/pdf/rcp01_06.pdf>. Acesso em: 30 mar. 2008.

Presidência da República. Lei $\mathbf{n}^{\circ}$ 9.394, de 20 de dezembro de 1996. Estabelece as diretrizes e bases da educação nacional. Brasília, 1996. Disponível em: < http:// www.planalto.gov.br/ccivil_03/Leis/L9394.htm>. Acesso em: 15 dez. 2007.

BRZEZINSKI, I. Pedagogia, pedagogos e formação de professores. 5. ed. Campinas: Papirus, 1996.

CANDAU, V. M. Magistério: construção cotidiana. Petrópolis: Vozes, 1997.

CURI, E. A matemática e os professores dos anos iniciais. São Paulo: Musa, 2005.

FACHIN, O. Fundamentos de metodologia. São Paulo: Atlas, 1993.

FREITAS, H. C. L. de. Formação de professores no Brasil: 10 anos de embate entre projetos de formação. Educação e Sociedade, Campinas, v. 23, n. 80, p.137-168, set. 2002.

GATTI, B. A.; NUNES, M. M. R. (Coord.). Formação de professores para o ensino fundamental: instituições formadoras e seus currículos. São Paulo: Fundação Victor Civita, 2008. (Relatório final: estudo dos cursos de licenciatura no Brasil: letras, matemática e ciências biológicas, 2). Disponível em: <http://www.fvc.org.br/estudos>. Acesso em: 05 dez. 2008. 
Formação inicial de professores e o curso de Pedagogia: ...

GAUTHIER, C. et al. Por uma teoria da pedagogia: pesquisas contemporâneas sobre o saber docente. Ijuí: Editora Unijuí, 1998.

GÓMEZ CHACÓN, I. M. Matemática emocional. Porto Alegre: Artmed, 2002.

KUENZER, A. Z.; RODRIGUES, M. F. As Diretrizes Curriculares para o Curso de Pedagogia: uma expressão da epistemologia da prática. Olhar de Professor, Ponta Grossa, v. 10, n. 1, p. 35-62, 2007. Disponível em: <http://www.revistas2.uepg.br/index.php/ olhardeprofessor/article/download/1474/1119>. Acesso em: 15 fev. 2008.

LIBÂNEO, J. C.; PIMENTA, S. G. Formação de profissionais da educação: visão crítica e perspectiva de mudança. In: PIMENTA, S. G. (Org.). Pedagogia e pedagogos: caminhos e perspectivas. São Paulo: Cortez, 2002. p. 11-57.

MAKAREWICZ, L. J. Crenças e atitudes declaradas por estudantes de um curso de pedagogia em relação à matemática e seu ensino: um estudo diagnóstico. 2007. $123 \mathrm{f}$. Dissertação (Mestrado em Ensino de Ciências e Matemática) - Universidade Cruzeiro do Sul, São Paulo, 2007.

MELLO, G. N. de. Formação inicial de professores para educação básica: uma (re)visão radical. São Paulo em Perspectiva, São Paulo, v. 14, n. 1, p. 98-110, jan./mar. 2000.

PIRES, C. M. C. Reflexões sobre os cursos de licenciatura em matemática, tomando como referência as orientações propostas nas Diretrizes Curriculares Nacionais para a formação de professores da educação básica. Educação Matemática em Revista, São Paulo, ano 9, n. 11, p. $44-56,2002$.

PONTE, J. P. da. A vertente profissional da formação inicial de professores de matemática. Educação Matemática em Revista, São Paulo, n. 11A, p. 3-8, 2002. Disponível em: $<$ http://www.educ.fc.ul.pt/docentes/jponte/docs-pt/02-Ponte\%20(SBEM).pdf >. Acesso em: 15 abr. 2007.

SERRAZINA, L. A formação para o ensino da matemática: perspectivas futuras. In: . (Org.). A formação para o ensino da Matemática na educação pré-escolar e no $1^{\circ}$ ciclo do ensino básico. Lisboa: Porto, 2002. p. 9-19.

A formação matemática dos professores das séries iniciais. APM, v. 14, n. 1, p. 109-31, 2005.

SHULMAN, L. S. Those who understand: knowledge growth in teaching. Educational Researcher, Washington, v. 15, n. 2, p. 4-14, 1986.

SILVA, C. S. B. da. Curso de pedagogia no Brasil: história e identidade. Campinas: Autores Associados, 1999.

SZTAJN, P. Conteúdos, atitudes e ideologia: a formação do professor de Matemática. In: CANDAU, V. M. (Org.). Magistério: construção cotidiana. Petrópolis: Vozes, 1997. p. $184-204$. 
Almeida, M. B.; Lima, M. G.

TARDIF, M. Saberes docentes e formação profissional. 7. ed. Petrópolis: Vozes, 2002.

TRICHES, J. O curso de pedagogia: projetos em disputa. In: SEMANA DE ENSINO, PESQUISA E EXTENSÃO DA UFSC, 6., 2007, Florianópolis. Anais... Florianópolis: Editora da UFSC, 2007. 1 CD- ROM.

Artigo recebido em 03/10/2011. Aceito em 15/01/2012. 